\title{
Developing Tests of Music Performance Improvisation a
}

\author{
Gary E. McPherson
}

The Oxford Handbook of Assessment Policy and Practice in Music Education, Volume 1

Edited by Timothy S. Brophy

Print Publication Date: Mar 2019 Subject: Music, Music Education

Online Publication Date: Jan 2019 DOI: 10.1093/oxfordhb/9780190248093.013.25

\begin{abstract}
Keywords
This chapter presents a survey of research on the development and validation of a measure to assess instrumentalists' ability to improvise music. It begins by framing efforts to distinguish between visual, aural, and creative forms of music performance, and the types of assessment tasks required to evaluate music performance improvisation. The chapter surveys a range of related measures that have been used to assess improvisational abilities in young developing musicians and provides a detailed description of the author's own Test of Ability to Improvise (TAI) that he has used with beginning, intermediate, and advanced level school instrumentalists. Included also are examples of the instrumentalists' improvisations and a discussion of the implications of the research findings for conceptions of musical development and practical applications within music education.
\end{abstract}

Keywords: improvised music, creative music performance, music performance, improvisational ability, school instrumentalist

\section{(p. 574) (p. 575) Introduction}

THIS focus of this chapter is on research aimed at developing and validating measures to assess instrumentalists' abilities to improvise music. The evidence discussed comes from my own teaching and research involving beginning, intermediate, and advanced level instrumentalists. Over a number of decades, my research interests have sought to clarify interrelationships among visual (i.e., perform rehearsed music, sight-read), aural (i.e., perform music from memory, play by ear), and creative (i.e., improvise) forms of musical performance (see Figure 25.1). 


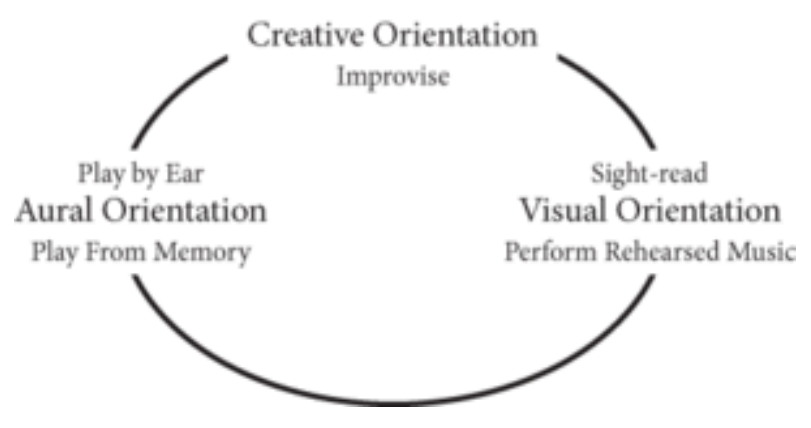

Figure 25.1 Visual, aural, and creative forms of music performance.

Given the dearth of information on creative forms of music performance, my explanation is meant to provide a personal perspective on assessing improvisational abilities of instrumentalists and vocalists who are learning in the types of instrumental programs we see in Western schools throughout the world. The basic technique could be applied to the assessment of improvisational abilities of students who are specializing in jazz and popular forms of music, but it is important to note from the outset that most of my research has been applied to students who are learning in traditional formal programs that emphasize learning notation and classical styles of performance.

It is therefore important to begin with a caveat. I am aware that every teaching situation is different, so the development of appropriate ways to assess students' abilities to improvise needs to begin with a thorough understanding of the context and the educational needs of the students. The development of appropriate music learning tasks that challenge students and that they find interesting and motivating is essential in situations where teachers intend to assess growth and achievement in this area. Consequently, the examples (p. 576) I advocate may be entirely inappropriate in other situations. It is my hope, however, that some of the techniques and the theory that underpins my ideas may prove beneficial for extending research and the improvement of teaching practice. Thus, to make best use of the techniques suggested in this chapter, music educators are encouraged to construct examples such as those identified in this chapter, but keeping in mind the age, instrument, and abilities of their students. This point is especially important given that much of the literature to date has focused on everyday practice rather than being grounded in theoretical frameworks that attempt to define the creative process more holistically.

This chapter describes the types of tasks that have been commonly used in research measures to assess improvisational abilities. This includes information on the types of evaluative criteria that are appropriate for the assessment of improvisation in research studies and the types of criteria used by the author in studies that have investigated stylistically conceived and freely conceived improvisation tasks. Included also is information on the reliability and validity of the author's Test of Ability to Improvise (TAI) and examples of responses from studies with high school instrumentalists (see McPherson, 1993, for a copy of the complete measure). The final section of the chapter discusses implications of 
the research for conceptions of musical development and the types of practical applications that arise from work within this area of research.

\section{Test of Ability to Improvise (TAI)}

In the process of designing appropriate tasks to assess young musicians' improvisational abilities, I consulted a number of prominent music educators, music education researchers, composers, and jazz improvisers, and reviewed available literature. I also pilot tested a number of techniques that I thought might be relevant to improvisation assessment with school-aged instrumentalists who were learning in formal school and community performance programs, where learning to perform by reading notation dominated instruction.

(p. 577) Seven types of tasks were explored. The first, Improvisation of a Closing Phrase, appears in various forms in classroom teaching, jazz instruction, and traditional forms of organ/keyboard instruction, and in some forms of external evaluation of performance ability, such as those used by the Associated Board of the Royal Schools of Music (see: http:// au.abrsm.org/en/about-abrsm/), which require candidates to improvise an answering phrase to a given opening phrase. Measures of musical creativity have also included a task that asks students to supply a closing phrase (see Figures 25.2a, 25.2b). This type of task is found in some of the earliest forms of creativity testing, such as Vaughan's (1971) Musical Creativity Test, designed for young musically untrained children, where students were asked to improvise an "answering" rhythm and "answering" closing phrase using tom tom and bells, respectively.

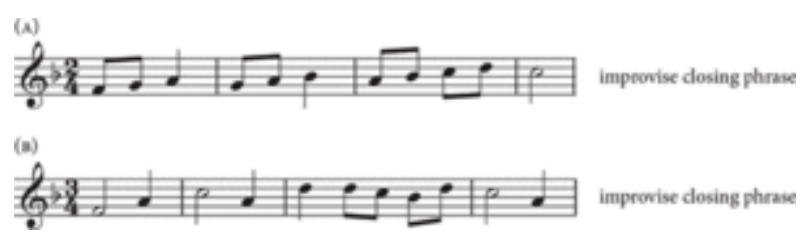

Figure 25.2a, $b$ Two improvised closing phrase tasks.

I decided to incorporate two short opening phrases in the TAI, which asked students to perform and continue a given phrase in a way that would provide a well-balanced melody comprising two phrases (i.e., antecedent-consequent structure). The task therefore, was to improvise a closing phrase that stylistically complemented the opening phrase, and that sounded finished. In this sense the stylistic requirements are set by the opening phrase, which finishes on the dominant and imposes a tonic to dominant-dominant to tonic structure for the two-phrase melody. To create a suitable response, the student would need to "feel" the shape and flow of the opening phrase in order to generate an appropriate closing phrase. There are numerous ways in which this could be achieved. For example, unity can be achieved by adopting a similar rhythmic pattern for the closing phrase; an ascending opening phrase might be mirrored by a descending answer; or repetition of 


\section{Developing Tests of Music Performance Improvisation}

sections of the opening phrase may form the basis from which a closing phrase is generated.

The second type of task, Improvisation on a Rhythmic Pattern, has been used to develop improvisational ability (Baker, 1969; Berkowitz, 1975; Campbell, 1990, 1991; Chase, 1988; Dean, 1989; Dickinson, 1964a, 1964b, 1964c; Frazee, 1987; Harvey, 1988; Hunt, 1968; Moore, 1990; Rowley, 1955; Schlieder, 1927; Simpson, 1963; Stubington, 1940; Texter, 1979; Thackray, 1978). As for the first task, the basis for a simple, well-balanced melody is predetermined by the rhythmic pattern, which students use to construct their own melody (see Figure 25.3). Of interest in this activity is the students' ability to shape their response by manipulating pitch in such a way as to fulfill the stylistic requirements of the task that will provide a musically interesting improvisation that finishes on the (p. 578) tonic in an assigned key. Of most concern was the ability of the students to orient themselves to the key, and to provide an interesting solution.

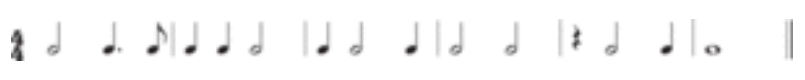

Figure 25.3 Improvisation on a rhythmic pattern.

The third task, Improvisation on a Motif, was designed to examine how young instrumentalists could generate a balanced melody of at least eight measures in length after being provided with a short introductory opening (see Figures 25.4a and 25.4b). Again, this form of exercise is common in the literature (Baker, 1969; Berkowitz, 1975; Chase, 1988; Coker, 1964; Dale, Jacob, \& Anson, 1940; Dean, 1989; Department of Education and Science, 1990; Dickinson, 1964a; Frackenpohl, 1985; Frazee, 1987; Froseth \& Blaser, 1980; Hunt, 1968; Judy, 1990; Kratus, 1990; Nicholls \& Tobins, 1937; Rowley, 1955; Sawyer, 1923; Schlieder, 1927; Stubington, 1940; Thackray, 1968, 1978; Wittlich \& Martin, 1989; Wunsch, 1972). Once again, we also see this type of task in early creativity measures such as Gorder's $(1976,1980)$ Measures of Musical Divergent Production. In the items chosen for use in the TAI, stylistic requirements of the melody are predetermined by the shape and rhythmic feel of the opening motif, which can be modified and adapted using a variety of musical techniques. For example, the motif could be repeated, inverted, transposed, varied by augmentation or diminution, or developed by fragmentation or elaboration. The taped instructions and sample performance that I devised for this task alerted the student to techniques (i.e., repetition, variation, and development) commonly used by performers while improvising on a motif.

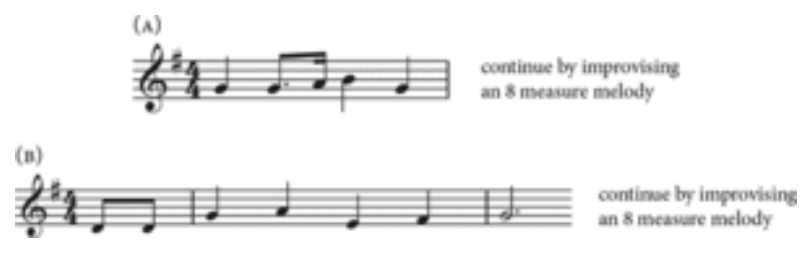

Figure 25.4 Two improvisation on a motif tasks. 
The fourth type of improvised response, Improvisation to an Accompaniment, is the basis from which most jazz and popular music is improvised (Baker, 1969; Coker, 1964; Dean, 1989). In addition, traditional forms of improvisation (Berkowitz, 1975; Chase, 1988; Dickinson, 1964c; Rosfeld, 1989; Rowley, 1955; Sawyer, 1923; Stubington, 1940; Thackray, 1978) and classroom/instrumental music instruction abound with examples of this form of improvisation (see Figure 25.5). Likewise, early creativity measures such as Vaughan's (1971) measure adopted this technique by asking students to improvise a melody over an ostinato accompaniment. For the purpose of the TAI, students were asked to complement the style of the accompanying passage in order to create their own improvisation. Students were therefore free to choose their own rhythm, but encouraged to restrict their playing to diatonic notes of the $\mathrm{C}$ major scale.

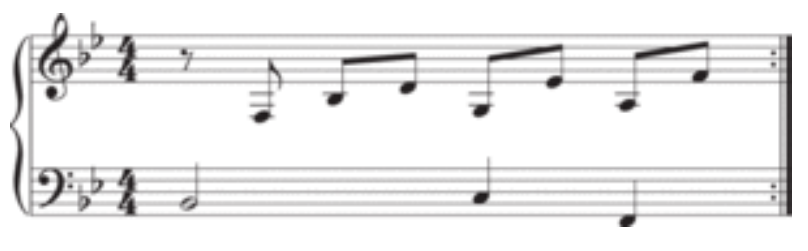

Figure 25.5 Improvisation to an accompaniment.

(p. 579) The final part of the measure was devised to investigate student ability to improvise in a "freely conceived" style. The development of this section was influenced by previous work by Gorder (1976, 1980), Flohr (1979), Priest (1985, 1988, 1989), Swanwick and Tillman (1986), and Webster $(1977,1979)$. Discussions with expert musicians and music educators suggested the need for this type of exercise as the most challenging component of the measure.

The first four TAI sections were labeled "stylistically conceived" because these tasks provided models in the form of set criteria that dominated the range of possible solutions available. For these tasks, the instrumentalists responded to externally generated restrictions.

In the final task the instrumentalist were challenged to provide their own "freely conceived" response by formulating their own set of internally generated parameters. The directions included the following statement:

For this task you are asked to perform an extended improvisation in any style or mood that you choose. You are free to play anything you like so let your musical imagination roam free. Your improvisation doesn't have to be in any particular key or conform to any set criteria. Just play your most interesting musical ideas.

Before you begin take time to think of interesting ideas that you could use as the basis of your improvisation.

Remember, you are completely free to do whatever you like-you may play for as long as you want! 


\section{Developing Tests of Music Performance Improvisation}

The directions allowed scope for the component of creative thinking together with the opportunity to examine more closely facets of ability to improvise in a "freely conceived" format. Incorporating this final item also allowed differences between "stylistically conceived" and "freely conceived" styles of improvising to be explored and investigated.

\section{Administering the TAI}

The TAI, as used in my research studies, includes carefully constructed musical examples and vocal directions to enable the test to be efficiently administered within a standardized format. Before commencing the tape, which included voice directions and taped (p. 580) performances on clarinet (or trumpet), students read an introductory statement aimed at familiarizing them with what was to follow. Instrumentalists are also asked if they understood the directions or if they had any questions before commencing each task. Practice activities for the first three items were in the form of musical examples and a discussion of what is required for each of the test items. These introductory examples and taped directions aimed to familiarize each player with the form of each task. In the first two items, involving question-answer phrases, students were given an opportunity to perform improvisations according to well-defined guidelines. The tasks were sequenced to allow for longer and more involved improvisations as the performer moves to each successive item (McPherson, 1993).

In my research, I typically asked students to perform a second improvisation for all but the final more extensive "freely conceived" task. However, this is not necessarily needed when working with students in an educational setting.

\section{Scoring the TAI}

The scoring procedure I developed for the TAI was based on a literature review and discussions with academics, music educators, and expert improvisers. At the time, no measures were available that specifically examined high school instrumentalists' ability to improvise in a "stylistically conceived," traditional setting, so a new method of scoring had to be devised, one that incorporated aspects of measurement of creativity in music as well as the skills thought essential by authors and experts in the area of improvisation.

My first task was to adequately differentiate improvisational ability with that of creative thinking in music, and to ensure that the criteria used for improvisation assessment were consistent with how practitioners and researchers viewed this form of performance. Here, my thinking was influenced by Gordon (1989):

it is easier to create than to improvise, creativity is a readiness for improvisation. Creativity is easier than improvisation, because there are more restrictions on a performer when he improvises than when he creates. For example, when a performer knows that he is to perform two tonal patterns in major tonality without any restrictions, he can be creative. When a performer knows that he is to perform two tonal patterns in major tonality and also that the first pattern is to be a tonic function and the second a dominant function, then he must improvise. Other 
restrictions may be in keyality, form, and style. When a student is creating he imposes restrictions upon himself. When he improvises, he is student to externally imposed restrictions. (pp. 71-72)

This view is consistent with methods researchers have adopted for the assessment of creativity and improvisation in music. It also contrasts measures of creative thinking, in which young untrained children are encourage to respond to open-ended tasks, with more "stylistically conceived" measures of improvisational performance. For example, the original form of Webster's (1989) Measures of Creative Thinking in Music, devised for young untrained children, involved evaluations using both objective and subjective techniques. Scoring was according to four factors:

(p. 581)

1. Musical Extensiveness: the amount of clock time involved in the creative tasks.

2. Musical Flexibility: the extent to which the musical parameters of

"high"/"low" (pitch); "fast"/"slow" (tempo) and "loud"/"soft" (dynamics) are manipulated.

3. Musical Originality: the extent to which the response is unusual or unique in musical terms and in the manner of performance.

4. Musical Syntax: the extent to which the response is inherently logical and makes "musical sense" (p. 3).

Vaughan's (1971) Musical Creativity Test involves six activities, with each task evaluated for fluency, rhythmic security, and ideation. Vaughan defines ideation as "the quality of variety and suitability within the given framework" (p. 65); for example, the manner in which a child improvises over an accompanying ostinato.

Gorder's $(1976,1980)$ Measures of Musical Divergent Production involves four short musical passages, which are scored using a procedure influenced by Guilford and Hoepfner (1971). These are:

1. Musical Fluency: the number of phrases produced.

2. Musical Flexibility: the number of phrases that used different kinds of musical content.

3. Musical Elaboration: the extent of content character over that necessary to produce a varied phrase.

4. Musical Originality: the rarity of usage of specific types of content.

5. Musical Appeal: the overall quality of the improvisation (global indication)

(Gorder, 1980, p. 36).

In this scoring technique Gorder $(1976,1980)$ deviates from the four basic divergent production abilities as explained by Guilford and Hoepfner (1971) by including a fifth factor (i.e., Musical Appeal), which he believes adds "a global musical ability that was in contrast to the specific divergent production abilities, and that enabled further profiling capability" (Gorder, 1980, p. 35). 
Webster (1979) provided an important contribution to the measurement of improvisational ability. His improvisation measure, administered to high school students involved in school music groups, involved four tasks. Activity one was a warm-up, while activity two involved free responses to a rhythmic and then melodic stimulus. Activity three asked students to perform Twinkle, Twinkle, Little Star and to then perform three variations on this melody. Activity four required students to improvise on an original melody, to create a transition from this improvisation to Twinkle, Twinkle, Little Star, and to conclude by again returning to an improvisation on the original melody. Like Gorder, $(1976,1980)$, Vaughan (1971), and Webster (1983a, 1983b), evaluative criteria were influenced by the theoretical literature of Guilford (1967) and Torrance (1966). In Webster's (1979) study improvisation was scored for fluency, flexibility, elaboration, and originality. However, each activity was scored for combinations of these factors, with no single task being designed to measure any one isolated factor (p. 232).

At the time I first started to devise assessment procedures for use in evaluating improvisational ability, a number of studies on jazz improvisation were also reviewed (p. 582) and considered (Aitken, 1975; Briscuso, 1972; Burnsed, 1978; Damron, 1973; McDaniel, 1974; Partchey, 1973; Pfenninger, 1990; Schilling, 1989). However, none of these techniques were considered relevant because of the distinctly different ways in which improvisations were performed, the low reliability estimates of some of the measures, the lack of information for some measures concerning the construction of the assessment criteria, or the tedious nature in which improvisational ability was assessed.

\section{Establishing the Assessment Criteria}

Figure 25.6 shows the flow chart that acted as the basis from which directions were formulated to evaluate each of the six "stylistically conceived" items on the TAI.

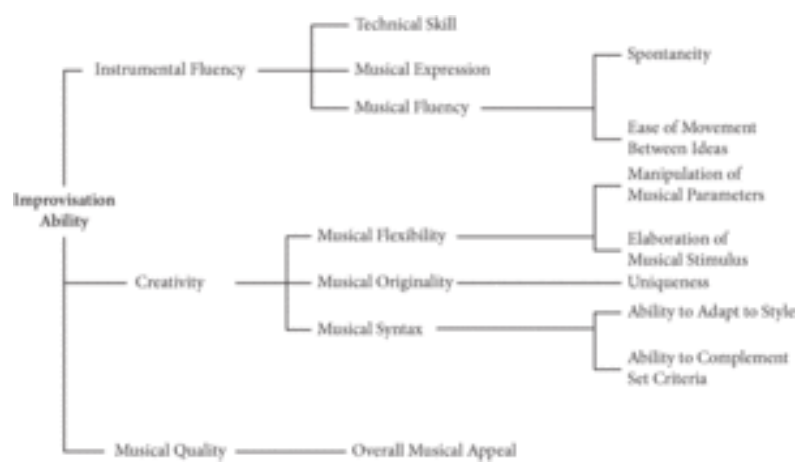

Figure 25.6 Assessment criteria TAI "stylistically conceived" items.

\section{Instrumental Fluency}

Instrumental fluency was defined as the ability to execute musical ideas clearly and accurately by responding freely, spontaneously, and with technical skill and musical expres- 


\section{Developing Tests of Music Performance Improvisation}

sion. Improvisers demonstrate fluency through their ability to perform in a spontaneous manner, such as by moving easily from one musical idea to another.

\section{Musical Syntax}

Musical syntax (consistency of style) refers to the ability to organize musical material by adapting to the prevailing style and complementing set criteria. Musical syntax is demonstrated by the way the improvisation demonstrates rhythmic feel, melodic sense, (p. 583) tonal organization, and shape (i.e., phrasing and form), and is able to provide a response that is inherently logical and that makes sense musically.

\section{Creativity}

Creativity is the ability to think divergently, as demonstrated in an original and imaginative product. This is evaluated through:

1. Musical Flexibility: the extent to which the improviser can manipulate musical elements (e.g., pitch, rhythm, articulation) through an elaboration of the musical stimulus (i.e., phrase, rhythm, motif, accompaniment).

2. Musical Originality: the extent to which the improviser can provide a musically unique or unusual response.

A unique or unusual response results from the manipulation and/or elaboration of pitch (e.g., use of sequence, diminution, inversion) or rhythm (e.g., augmentation, diminution, dotted versus nondotted, metric versus syncopated), or other musical elements (e.g., timbre, articulation, dynamics).

\section{Musical Quality}

Musical quality (overall musical appeal) is the ability of the improviser to perform fluently creatively conceived material that complements existing musical criteria or constraints. This global rating can be used to provide an indication of the overall musical appeal of the improvisation and the extent to which the performance was committed, played expressively, and in a musically meaningful and creative manner. Figure 25.7 shows the flow chart that acted as the basis from which directions were formulated to evaluate the final "freely conceived" item on the TAI. 


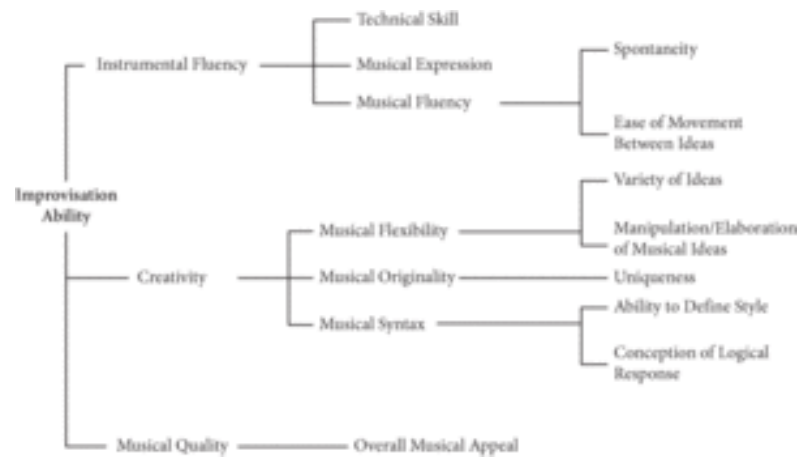

Figure 25.7 Assessment criteria TAI "freely conceived" items.

For the "freely conceived" item the directions for the instrumental fluency dimension were identical to that used for the "stylistically conceived" items. The dimensions of musical syntax, creativity, and musical quality differed from those of the "stylistically conceived" items as indicated in what follows.

\section{Musical Syntax}

The improviser provides a response that is inherently logical and that makes musical sense. Musical syntax is demonstrated in the degree to which the improvisation demonstrates rhythmic feel, melodic sense, tonal organization, and shape (i.e., phrasing and form).

\section{Creativity}

This can be evaluated through an analysis of:

1. Musical Flexibility: the extent to which the improviser can generate differing musical ideas and manipulate/elaborate these ideas during the course of the improvisation.

2. Musical Originality: the extent to which the improviser can provide a musically unique or unusual response.

A unique or unusual response can result from the manipulation and/or elaboration of pitch (e.g., use of sequence, diminution, inversion) or rhythm (e.g., diminution, (p. 584) augmentation, dotted versus nondotted, metric versus syncopated), or other musical elements (e.g., timbre, articulation, dynamics).

\section{Musical Quality}

This global rating was used to indicate the overall musical appeal of the improvisation and the extent to which it was played expressively and in a musically meaningful and creative manner. 


\section{Final Scoring Method}

In my original research studies, I used a five-point rating scale to assess each of the essential criteria on all seven items of the TAI, but for teaching contexts and added discrimination I would now recommend that this be expanded to a 10-point scale or even a percentage so that the four dimensions can be summed for a total improvisation score for each task (see Table 25.1). 


\section{Developing Tests of Music Performance Improvisation}

Table 25.1 Improvisation Rating Scale

\section{Hesitant \& Laboured}

\begin{tabular}{|c|c|c|c|c|c|c|c|c|c|c|}
\hline \multirow[b]{2}{*}{$\begin{array}{l}\text { Instru- } \\
\text { mental } \\
\text { Fluen- } \\
\text { cy }\end{array}$} & \multicolumn{5}{|c|}{ Hesitant \& Laboured } & \multicolumn{5}{|c|}{ Spontaneous \& Confident } \\
\hline & 1 & 2 & 3 & 4 & 5 & 6 & 7 & 8 & 9 & 10 \\
\hline & \multicolumn{5}{|c|}{ Illogical } & & & & & Logical \\
\hline \multirow[t]{2}{*}{$\begin{array}{l}\text { Musi- } \\
\text { cal } \\
\text { Syntax }\end{array}$} & 1 & 2 & 3 & 4 & 5 & 6 & 7 & 8 & 9 & 10 \\
\hline & \multicolumn{5}{|c|}{ No Uniqueness } & & & & \multicolumn{2}{|c|}{ Marked Uniqueness } \\
\hline \multirow{2}{*}{$\begin{array}{l}\text { Cre- } \\
\text { ativity }\end{array}$} & 1 & 2 & 3 & 4 & 5 & 6 & 7 & 8 & 9 & 10 \\
\hline & \multicolumn{5}{|c|}{ Unappealing } & \multicolumn{5}{|c|}{ Appealing } \\
\hline $\begin{array}{l}\text { Musi- } \\
\text { cal } \\
\text { Quality }\end{array}$ & 1 & 2 & 3 & 4 & 5 & 6 & 7 & 8 & 9 & 10 \\
\hline
\end{tabular}

\section{Spontaneous \& Confident}

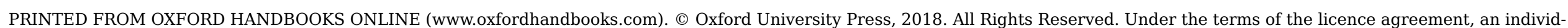
ual user may print out a PDF of a single chapter of a title in Oxford Handbooks Online for personal use (for details see Privacy Policy and Legal Notice). 


\section{Reliability and Validity}

I analyzed data using the multitrait-multimethod (MTMM) approach formalized by Campbell and Fiske (1959) to find evidence of convergent and discriminant validity for each of the performance measures, and to determine the extent to which the attributes measured by the three judges predicted the specific trait in question (i.e., each individual item on the test). A separate matrix was computed for each of the measures according to scores for each of the three independent judges on each of the test items. Results for each (p. 585) of the measures showed a consistent pattern that satisfied the four criteria established by Campbell and Fiske (McPherson, 1993, 1995, 2005).

In addition, since few measures have been developed to assess improvisational ability, particularly with high school-age instrumentalists, it was necessary to establish the validity of the four evaluative criteria (i.e., instrumental fluency, musical syntax, creativity, and musical quality) used in the TAI. Using the MTMM, indications of convergent validity were obtained to gauge the level of agreement between each of the four separate criteria used to evaluate the seven items on the TAI, and the three separate evaluations by the judges for each of these criteria. Discriminant validity estimates were obtained to assess the level of correlation between each of the four criteria with the other three. Results showed a consistent pattern of correlations when analyzed according to each of the seven test items. As would be expected, the global evaluative dimension of musical quality tended to be more highly correlated with the other three evaluative criteria than correlation patterns between the other three dimensions (McPherson, 1993, 1995).

The interjudge correlations for the three judges who scored the TAI range from .71 to .94 for the four separate item assessments, and from .89 to .97 for the composite marks for each individual task on the measure. The Cronbach alpha indication of internal consistency was .90 (.90 standardized item alpha).

\section{Original Study Sample}

In the original study (McPherson, 1993), average scores for the TAI when used with students who had between 2 and 6 years of instrumental learning, revealed a good spread of marks from about $5 \%$ to $95 \%$ on the total measure. The sample was split into two groups. Group 1 included clarinet and trumpet students who had studied these instruments for 2 to 4 years and were undertaking Australian Music Examination Board (AMEB) externally assessed examinations at Grade 3 and 4 level of the AMEB syllabus. They (p. 586) were in school years 7 to 9 (ages 11.5 to 15). Group 2 included clarinet and trumpet students who had studied these instruments for 4 to 6 years and were undertaking AMEB examinations at Grade 5 and 6 of the same syllabus. These students were in school years 10-12 (ages 14.5 to 18.5). As would be expected, the more experienced musicians in AMEB grades 5 and 6 provided more sophisticated responses than their younger, less experienced counterparts. Inter-item correlation coefficients for the TAI were all significant $(p<.01)$ and ranged between .46 and .68 . 


\section{Test of Ability to Improvise}

This section presents a discussion of the Test of Ability to Improvise and the studies pertaining to this test.

\section{Repeated Attempts on the TAI}

During the administration of the TAI students were given an opportunity to perform a second improvisation for each of the six "stylistically conceived" items on the test. A second attempt was not allocated for the "freely conceived" item, as this would have been too time consuming, considering the time limitations of the sessions and the concentration span of the students.

To assess whether these second attempts were significantly better than the first attempt, the second responses for 46 students participating in the study were combined with the first 101 performances of the combined population. During the analysis period, judges assessed a total of 147 improvisations for each of the six "stylistically conceived" TAI items, without any knowledge of the student, or whether it was their first or second attempt.

Analysis using the Scheffé multiple comparisons procedure revealed no statistically significant differences between the first and second responses for each of the six "stylistically conceived" improvisational tasks. The means for the first and second attempts of each item were very similar. However, the item that showed the greatest improvement for the second attempt was the rhythm item. In this item students were shown a rhythmic pattern and asked to improvise a melody to complement the notation (see McPherson, 1993, 1995).

\section{Analysis of Transcriptions of Student Responses}

This section presents a discussion of the results of the TAI and what the analyses of these results revealed.

\section{(p. 587) Closing Phrase 1 and 2}

The improvisations required for the two Closing Phrase items were the shortest tasks on the TAI. In these items students were asked to improvise a short closing phrase that complemented the given opening phrase. Because this task requires only a four-measure response, the resulting improvisations were somewhat pattern bound. The performer was restricted to a four-measure closing phrase in F major that ends on F. This stimulus therefore allows little scope for an improvisation to deviate far from the norm.

At the time of constructing the TAI it was considered important to include these items, so that a full range of improvisation, from the simplest and most restricted, to those that were more challenging and freely conceived, could be analyzed. I hoped that restricting the possibilities for response on the first two items of the test might allow the researcher to analyze essential performance characteristics that may be more difficult to observe in longer, more complex improvisations. In addition, the short period of 15 to 20 seconds al- 


\section{Developing Tests of Music Performance Improvisation}

located for each student to contemplate the requirements before commencing offered an opportunity to investigate how more gifted students prepared their response and thereby were able to plan their improvisation. From the outset it was assumed that a good improviser would provide an interesting and creative response no matter what the restrictions.

The most important question considered in the analysis of the closing phrase responses concerned the ability of students to provide a response that complemented the opening figure. The best responses came from students who had mentally prepared at least part of their response before commencing to play, although it could be argued that this is more "composition" than "improvisation." However, as experienced improvisers understand, improvisation often involves some form of planning prior to the performance because the process of improvising includes the ability to translate a preconceived idea into the movements necessary to perform correctly this intention on a musical instrument. A study by Hargreaves, Cork, and Setton (1990) confirmed these observations by highlighting the different strategy used by novice and expert jazz pianists. A distinguishing characteristic of expert improvisers in this study was their ability to start their performance with an overall strategy or plan.

The range of improvised closing phrases for the first two items on the TAI was extensive. They ranged from incomplete, hesitant statements of a couple of notes, to well-shaped, innovative phrases that adequately complemented the opening phrases. The lowest-scoring improvisers were characterized by a lack of ability to adhere to a four-measure statement, poor control of rhythm and pitch, and a dearth of ideas. Close observation of the players during the sessions followed by careful listening to the taped performances indicated a serious lack of ability by these students to coordinate ear and hand. Many of these improvisations appeared to be "accidental" in that the instrumentalists seemed unable to prepare an improvisation in any "holistic" sense, and to thereby show evidence of an ability to "think in sound." It was as if these performers had prepared the opening note or group of notes, but were unable to maintain the flow of ideas throughout the four measures. They tended to play what instinctively had been (p. 588) ingrained, rather than anything they had prepared mentally beforehand. Because the lowest-scoring improvisations showed a distinct lack of ability by the performer to audiate sounds as they were being played, they fit into the category described by Kratus (1990) as "exploration." These improvisers worked at a conscious level, not yet having assimilated the technical, aural, kinesthetic, and theoretical aspects of their playing.

The majority of improvised responses showed evidence of the players' intentions, however unsuccessful. It was clear that most of the players could provide a four-measure closing phrase, perform in correct tempo and key, and pick up the essential characteristics of the opening phrase by providing a well-shaped response that incorporated a similar rhythm and/or pitch pattern to the opening. Many of the better improvisers (1) performed confidently and spontaneously; (2) were capable of using the exact rhythm of the opening phrase, or subtle variations of it; (3) displayed a good sense of direction and overall phrase shape; (4) used appropriate articulations; (5) maintained the flow of their ideas; 


\section{Developing Tests of Music Performance Improvisation}

(6) easily conformed to the prescribed criteria; and (7) provided a musically satisfying response.

The highest-scoring responses displayed one further characteristic. These improvisations displayed not only technical control and theoretical understanding of the requirements but also originality as evidenced in their ability to stretch out and take risks. It was as if these improvisers had assimilated the technical, theoretical, aural, and kinesthetic aspects of their playing into one, and were thereby able to reach out beyond the norm to provide something unique or novel. Examples of "stretching out" were observed in (1) the wider choice of starting notes (one student started on the high A of the trumpet), (2) the more sophisticated sense of shaping (i.e., use of sequences, inversion of opening figures, rhythmic disruption through use of dotted rhythm and eighth notes, and wider range), (3) greater use of expression and tone color, and (4) an intuitive feel for the harmonic implications of the closing phrase. These techniques helped make the improvisation more interesting for the listener.

\section{Rhythm}

The Rhythm item allowed the study of a different dimension of an ability to improvise. Unlike the other items, where the improviser translates an aural conception into the physical movements necessary to perform this conception on a musical instrument, this item required the performer to process music visually at the same time as improvising a response based on this rhythmic pattern. Essentially, the task required the student to translate the rhythmic pattern (comprising familiar rhythmic patterns in $\frac{4}{4}$ time) into an interesting six-measure melodic response. For this to be possible, the performer must first be able to read and aurally comprehend the rhythmic pattern. The improviser must also be able to integrate this aural image with appropriate pitches to construct an interesting solution.

The highest-scoring improvisers were able to continue their response and perform the rhythm pattern correctly. These improvisers were clearly able to bring meaning to the notation and to conceive of the pattern holistically (rather than in individual notes or small patterns). They were more likely to (1) start on a note other than F, (2) use more (p. 589) leaps in their melody, (3) provide a strong sense of key by outlining the tonic triad in the first measure, and (4) provide a strong feeling of finality (e.g., by approaching the tonic from above and below). The ability of these improvisers to audiate the rhythmic pattern enhanced their skill to organize the music into logically conceived patterns. Because these improvisers could comprehend the rhythm on which to improvise they could work with a more definite aural orientation. Because of these features, high-scoring improvisers demonstrated the most sophisticated working styles. In summary, they seemed more capable of working at a more global level, of working in larger rhythmic units, and of maintaining the flow of their ideas throughout their improvisation.

The lowest-scoring improvisers were plainly not as efficient processors of the rhythm as their older more experienced colleagues. They were more likely to make errors in pitch (e.g., B natural instead of B flat), and to provide a less key-oriented response. This was 


\section{Developing Tests of Music Performance Improvisation}

evident in the stepwise motion of the opening measures and the weaker sense of finality (as evident in those responses that approached the tonic by stepwise movement, repetition, or inappropriate leap).

Analysis of the tapes and transcriptions also showed that many of the performers were not able to improvise an interesting melody using the assigned rhythmic pattern. It was as if the visual orientation involved when processing the notation made it difficult for the improviser to think aurally. Many of the improvisations used stepwise movement and repeated pitches, and many were poorly shaped. This gave the impression that many students improvised by focusing their attention on the individual notes within the notation. These improvisers lacked an ability to comprehend the pattern as a whole, or to anticipate the flow of the rhythm as they performed their response.

In many cases the process of translating the visual notation into an aural image clearly impeded fluency and spontaneity. Low-scoring improvisations were characterized by a dearth of ideas that were often unconnected. It was as if these students were trying to force the rhythmic pattern to fit their own conception rather than complement the existing framework. Above all, the improvisers worked at a conscious level and the resultant products largely centered around the physical and theoretical aspects of playing (e.g., scalewise movement, repetition). There was little evidence that they were able to respond to the demands of divergent thinking to explore the range of possibilities that existed for providing an interesting solution, or worked far enough ahead to ensure fluency and an interesting response. An ability to think divergently was therefore stifled as these students tried to adjust to the requirements. Many of these students performed B naturals and other incorrect notes in F major. They were also more likely to hesitate, stop, or restart their performance.

The lowest-scoring improvisers were incapable of performing the rhythm fluently and used repetition or stepwise movement throughout. In addition, they made numerous pitch errors. Also evident was a weak sense of key and a poor sense of the harmonic implications of their response. For these improvisers, processing the visual information and then coordinating the aural conception with the physical movement necessary to perform the improvisation on an instrument was a major problem. This was the least efficient working style.

(p. 590) The findings presented here parallel observations by jazz educators (Baker, 1979), who suggest that improvisation by sight stifles creativity and instrumental fluency. Improvisers who rely on "reading" the chord progression as they improvise are often hampered in their ability to feel the flow of the accompaniment. They are also more likely to think and work in small units rather than "holistically." This type of improvisation can lead to a disjointed approach without a clear sense of organization. It can also lead to a rigid focus on only one element (i.e., pitch or rhythm) without an ability to remain open to other ideas or to work with other players. Improvisers who have not memorized the chord progression and therefore need to read the changes by sight are often more restricted in what they play compared to those of similar ability who have memorized the changes and 
improvise without the music (Baker, 1979). In this sense, improvisation by sight as opposed to improvisation by ear can have a stifling influence on the ability of the performer to create an effective and well-shaped improvisation. Clearly evident in the performances on this task was the impression that spontaneity and creativity was impeded for each performer who was unable to fully audiate the rhythmic pattern.

\section{Motif 1 and 2}

For both Motif 1 and Motif 2 students were asked to use the prescribed opening melodic figures as the basis of an improvised performance of at least eight measures in length. Similar to the preceding items, there was a wide range of responses showing a diversity of skill and ability levels. The lowest-scoring responses were typically short statements of less than eight measures. These improvisations tended to use a restricted range with mostly stepwise movement and occasional leaps of thirds and fourths. Clearly, these improvisers were unable to manipulate, elaborate, or extend the given opening figure. Consequently, the improvisations also displayed a poor sense of phrase balance and were performed in a hesitant manner, leaving the impression that the player was unable to maintain a flow of ideas. These improvisations also tended to be unimaginative, random-like melodies that lacked musical logic and were stylistically inconsistent with the requirements expected. The improvisers were also unable to construct a string of ongoing twoor four-measure phrases, and to improvise a suitable second phrase, preferring instead to repeat ideas expressed in the first phrase. When breakdowns occurred, they typically gravitated back to the opening figure, with meaningless repetition, not knowing how to move beyond their opening ideas. Consequently, for these students, an ability to think divergently and creatively was lacking; they seemed oblivious to the possibilities that existed for providing an interesting solution. These features can be seen in the responses for Motif 2, shown in Figures 25.8 and 25.9.

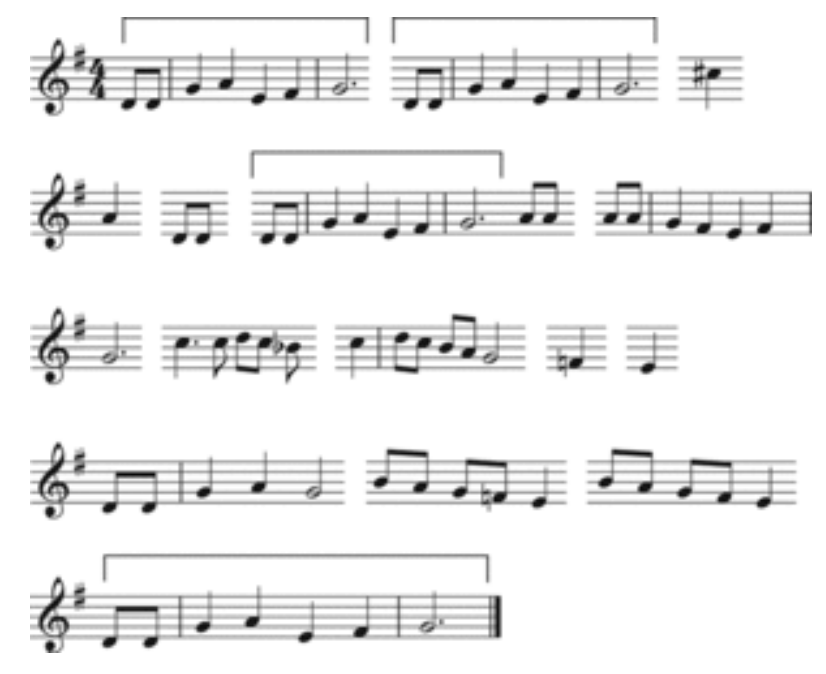

Figure 25.8 Group 1 low scoring response (motif 2). 


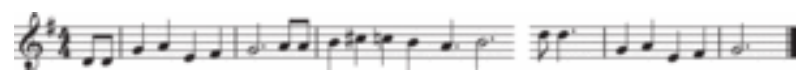

Figure 25.9 Group 2 low scoring response (motif 2).

In contrast, high-scoring students were able to provide an intelligent and musical response. An essential difference between students, as determined by length of time spent learning their instruments, was that the older more experienced musicians typically provided a longer and more interesting solution.

Figures 25.10, 25.11, and 25.12 are examples of some of the responses. High-scoring students (1) easily maintained a steady pulse; (2) seemed to have an intuitive feel for four (p. 591) two-measure phrases, and an eight-measure response; (3) were capable of using the exact rhythm of the opening phrase or employing subtle variations of it; (4) used range to enhance the shape of their response; (5) moved easily within the key displaying a strong kinesthetic feel for G major; (6) provided a strong sense of cadence; (7) finished on the tonic; (8) mirrored patterns of the opening phrase or constructed logical sequences; (9) used inversion and repetition; (10) constructed logical balanced phrases using antecedent-consequent phrase relationships to enhance structure; (11) varied, manipulated, and elaborated the opening motif; (12) maintained the flow of ideas; (13) sustained the response throughout the entire improvisation; and (14) dealt with melody, phrase, and rhythm in a spontaneous and confident manner. It was obvious that these elements had been assimilated technically, aurally, and kinesthetically. Examples of these improvisations are given in Figures 25.10, 25.11, and 25.12.

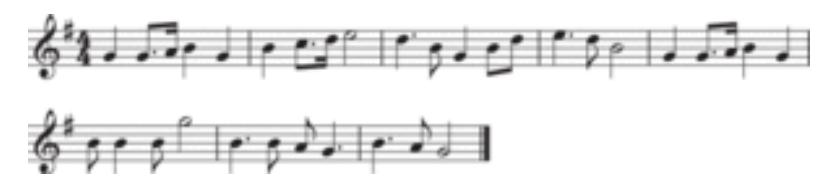

Figure 25.10 Group 1 high scoring response (motif 1).

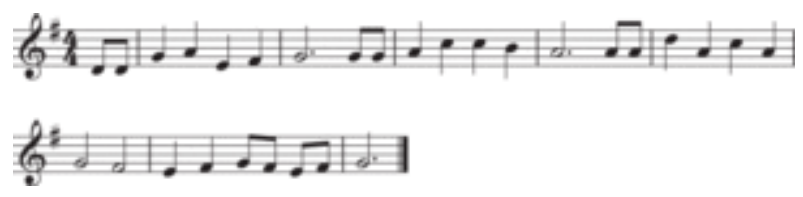

Figure 25.11 Group 1 high scoring response (motif 2). 


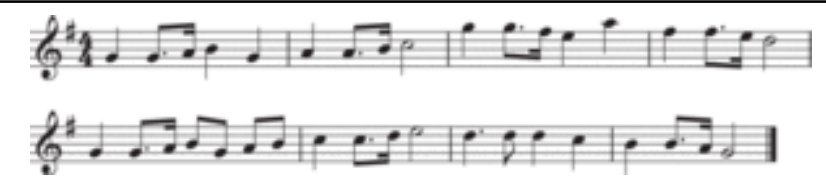

Figure 25.12 Group 2 high scoring response (motif

1).

(p. 592) Interestingly, analysis of transcriptions shows that the majority of performances for both items in this section were exactly eight measures in length. Discussions with students after their performance revealed that many were not consciously trying to perform an eight-measure response. Most were unaware of the length of their improvisation, frequently expressing surprise that their performance had been exactly eight measures. For these students an eight-measure response resulted from the four two-measure phrases they had used to structure their improvisation. This aspect had been felt intuitively and was not consciously preplanned.

\section{Accompaniment}

An accompaniment figure was performed using an electronic keyboard and copied onto a recording device that could be used with the students (see Figure 25.5). Students were asked to improvise an interesting melody using only notes of the $\mathrm{C}$ major scale that captures the style of this accompaniment (i.e., based on chords I-ii-V).

Many of the poorest responses on this item showed a surprising lack of ability by the musicians to coordinate their playing with the accompaniment. These students tended to force their ideas to fit the existing framework with the result that their improvisation (p. 593) seemed totally at odds with the chordal progression with which they were performing. Low-scoring responses also displayed a limited repertoire of rhythmic devices, often repeating the first idea over and over again. They tended to use mostly stepwise movement, with occasional leaps of thirds and fourths. These responses also lacked a sense of key, despite being in the key of $\mathrm{C}$ major, and were typically rambling, disjointed melodies often without a logical formation. The majority of these improvisers were unable to use sequences, rhythmic changes, or other devices to shape and enhance their response. Often they were unable to improvise a suitable second phrase, preferring instead to repeat ideas expressed in their first phrase, restrict their performance to the middle register, and perform unimaginative improvisations with little insight about what the accompaniment was "suggesting." These students displayed a lack of coordination between ear and hand, as if their improvisation was "accidental" rather than intuitive. Typical examples of these responses are shown in Figures 25.13 and 25.14. 


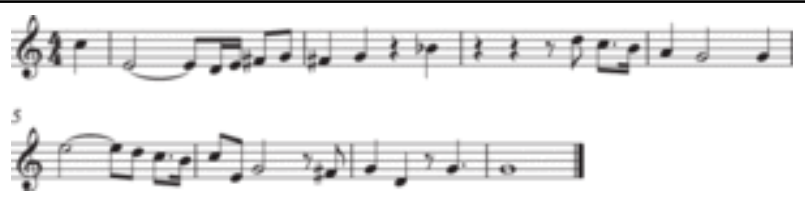

Figure 25.13 Group 1 low scoring response (accompaniment).

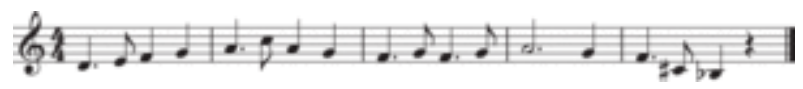

Figure 25.14 Group 1 low scoring response (accompaniment).

The finest improvisations from both groups showed mature playing from innovative, skilled musicians. Many of these responses were musically very satisfying, and displayed a strong sense of personal involvement in the performance. There was also evidence of a strong kinesthetic feel for the instrument and an ability to make sense of the ideas and requirements. These students were also capable of sustaining their response throughout the entire phrase and of providing an improvisation with delicate expression (see Figures 25.15, 25.16, and 25.17).

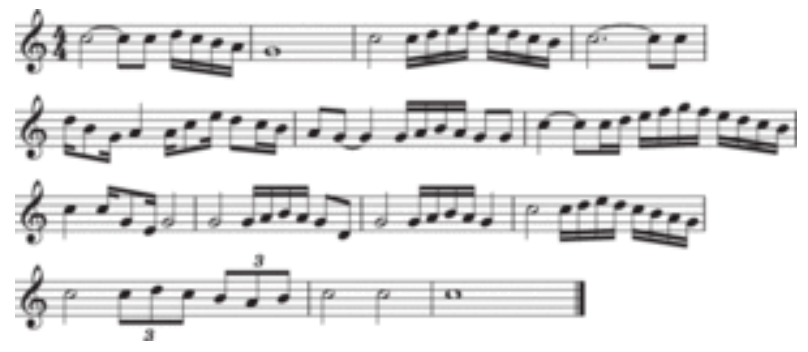

Figure 25.15 Group 2 high scoring response (accompaniment).

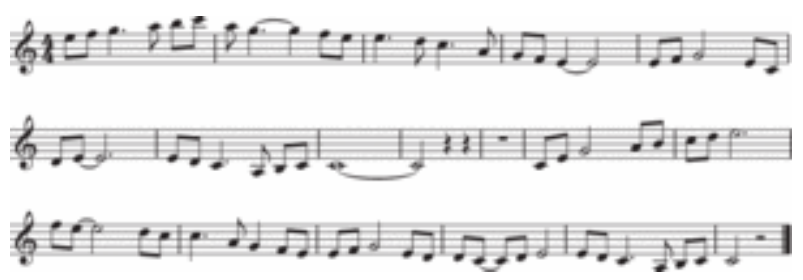

Figure 25.16 Group 2 high scoring response (accompaniment). 


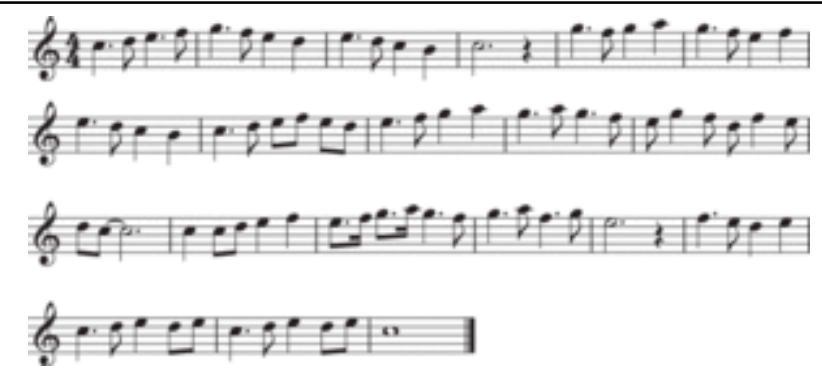

Figure 25.17 Group 1 high scoring response (accompaniment).

\section{Freely Conceived}

Unlike the first six "stylistically conceived" items, the final task on the TAI asked students to perform an extended improvisation in any style or mood they chose. Of interest in this item was the ability of students to define their own style and to construct an improvisation that was both tastefully and logically conceived.

Analysis of transcriptions and master tapes revealed that many of the characteristics identified for the preceding items were also pertinent for this item. However, since this (p. 594) (p. 595) item allowed more freedom for response, and typically involved a much longer improvised performance, there are a number of additional comments that can be made.

The poorest responses displayed an almost total lack of ability by the performer to start with an appropriately conceived opening motif that could be used as the basis for an interesting improvised performance. Figure 25.18 shows the transcription of one performer, who, devoid of ideas, was unable to elaborate or extend his opening figure and to use it as the basis for his improvisation. For this performer, a lack of coordination between ear and hand was evident in his playing. It was as though this player's improvisation centered on the technical and physical aspects of producing a response that was a secure part of his repertoire. Because of the stepwise movement and lack of elaboration and manipulation of musical parameters there is a feeling that the student's fingers were "walking" between notes without a clear impression that he had really planned what to do. Above all, this improvisation lacks a suitable preconceived idea that could provide the basis or "spark" to ignite the imagination and provide coherence to the rest of the improvisation.

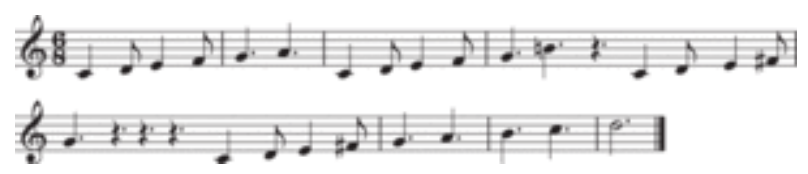

Figure 25.18 Low scoring response (freely). 
At a slightly higher level of performance were improvisers who were more capable of moving beyond their opening phrase, and who displayed some sense of phrasing and shape. Figure 25.19 is an example of this type of response. Unfortunately, however, these students were limited in their ability to sustain their response throughout the entire improvisation and to extend or elaborate their ideas. Improvisation for these students was limited to a short, predictable response with few distinguishing characteristics or sparks of imagination or inventiveness.

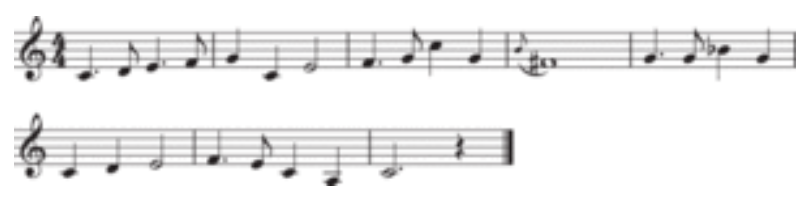

Figure 25.19 Group 2 low scoring response (freely).

Low-scoring improvisers who provided a longer response than the ones shown previously were typically unable to respond with a clearly defined and shaped performance. These improvisations were often disjointed and fragmented, and lacked a coherent conception. Low-scoring students displayed a limited repertoire of rhythmic devices, (p. 596) tending to repeat the same rhythm over and over again. They were also more prone to use a restricted range, and where leaps occurred, they were often illogical and typically at points where the response broke down or where the student hesitated. In addition, these improvisers often performed rambling and disjointed pieces and tended to limit their response to a repetition of their first basic idea. They were also unable to control their performance, as seen in the number of notes performed outside the key or tonal center in which they were improvising.

In contrast to the limited improvisational ability of some of the students, many of the improvisations were musically satisfying and noteworthy. Economy of means was a characteristic of the better improvisations, especially for less experienced players. Many performers did not employ an extensive range of rhythmic devices but nevertheless performed an effective and original improvisation. Of prime importance to an effective performance was the ability of the improviser to sustain the flow of ideas, to connect ideas, and to end their performance effectively and musically.

A distinguishing characteristic of the best improvisations was the quality of the first basic idea chosen for performance. It was often the case that the better the quality of the opening statement the better the overall performance. Some students opened with an idea that was more technically than musically conceived. These improvisers chose a scale-like run, a tongued (or slurred) passage in thirds, or some other figure that had limited use as an opening motif for an extended improvisation. The best improvisers were those students who chose an interesting opening figure that allowed development and extension, and that acted as a "spark" to ignite their musical imagination. 


\section{Developing Tests of Music Performance Improvisation}

Another characteristic of the better improvisations was the degree to which the per-

former displayed an intuitive feel for improvising in a freely conceived idiom. This was observed in a number of ways. First, there was the degree to which the performer had control of the instrument, and the quality of the ear-to-hand coordination. This was indicated in how well the player could finger the notes they were thinking, without making errors in accidentals or hesitating during their performance. It was also evident in the way in which an improviser restricted their options. The best improvisers were those students who manipulated, elaborated, and extended a few basic ideas, without "overplaying" or trying to do too much during their improvisation. These improvisers performed coherent improvisations that displayed an intelligent sense of shape.

Overall, these performances were rarely rushed. The performance moved naturally and effectively from one idea to another only when the music demanded a change of direction. The best performers were also the musicians who made themselves aware of the possibilities before commencing their performance. These characteristics have been cited in other discussions (e.g., Hargreaves et al., 1990; Pressing, 1988) as essential for a wellconceived and presented improvisation. Pressing argues that competent improvisation is a decision-making process in which an improviser begins with a musical idea that is then extended or elaborated using features inherent in the opening conception. This was clearly evident in one of the better improvisations (see Figure 25.20), where a female trumpeter extends and elaborates her opening motif in $\mathrm{G}$ minor and uses this to provide coherence and to shape her whole improvisation.

(p. 597) (p. 598) In general, the shorter improvisations displayed a clearer sense of shape than did the longer responses. Many of the longer responses for Group 1 students were described by one evaluator as "rambling soundscapes." Shorter responses from both groups were more likely to exhibit a clearer sense of form and overall shape.

When the three evaluators met approximately eight months after the initial evaluative period to discuss the performances on tape, they showed an uncanny ability to tell whether the improvisation they were listening to was performed by a male or female student. This was especially true of the most experienced musicians. Although no significant difference was found for gender in terms of the scores given for each section of the test, there were qualitative difference in the responses that were evident in many, but not all, of the improvised performances for the "freely conceived" section of the TAI, especially for students in Group 2. Female students tended to play expressive improvisations that were often slower and had more space and rests. Some were free in style, displaying a sophisticated sense of phrasing and time. Consequently, they were less "busy" with their choice of notes, and the ways in which they expressed their ideas. For Group 2, 22 of the sample of 25 female students had elected school classroom music (in comparison to 14 of the 23 male students). The "freely conceived" improvisations of female students in Group 2 typically demonstrated the influence of prior exposure and experience of composing in elective music classes. 
Male students of Group 2, on the other hand, tended to provide more outgoing, faster, and busier improvisations than females. Many of these performances used a jazz or pop idiom and were more like the improvisations one would expect in a stage ensemble performance of a jazz or rock arrangement. However, these characteristics did not result from an increased exposure by males to jazz/pop ensembles. On the contrary, for the sample chosen for this study there were identical numbers of Group 2 males and females (i.e., eight) who were performing with jazz ensembles on a regular basis.

Figures 25.20 and 25.21 show two examples of high-scoring responses in this section of the battery. The first is by a female and the second by a male.

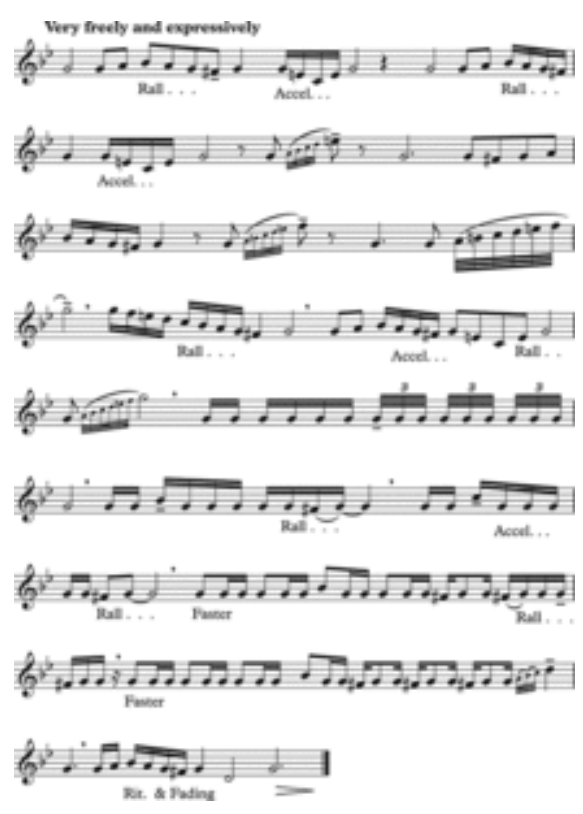

Figure 25.20 Group 2 trumpet high scoring female response (freely). 


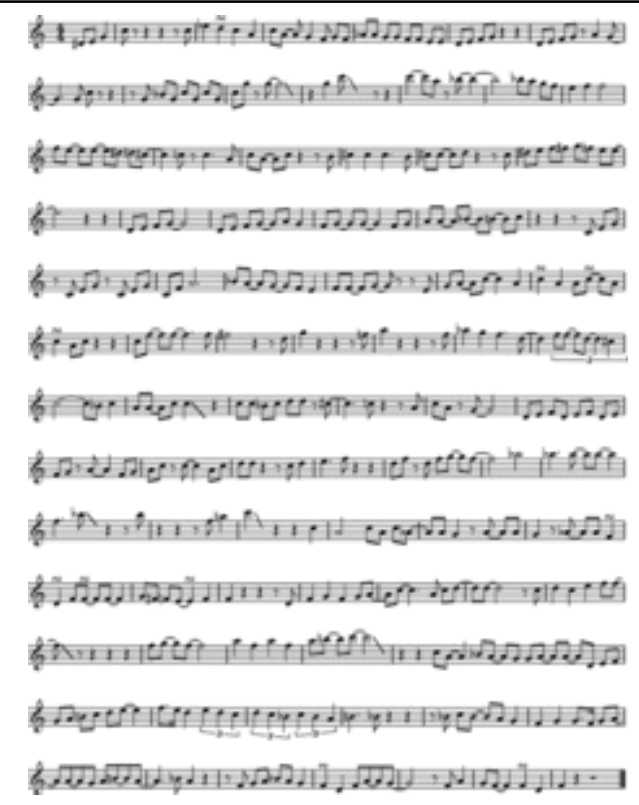

Figure 25.21 Group 2 trumpet high scoring male response (freely).

There were other aspects between groups that were also worthy of mention. First, an analysis of starting notes in the freely conceived item revealed only a slight difference in the choice of starting notes according to musical experience, with more than $50 \%$ of the students starting their improvisation on C. Analysis of the tonal center used for the improvisations was also unremarkable. Almost three-quarters of the improvisations used a tonal center of $\mathrm{C}$, with far fewer adopting $\mathrm{G}$ and $\mathrm{E}$ and a very small percentage (around $3 \%)$ displaying a total lack of tonal center.

Although not as obvious, there were subtle differences between instruments in the extent of idiomatic devices that the soloist used. Clarinetists were more likely to use a wider range, employ wide leaps, and use other idiomatic devices typical of performance on this instrument. Likewise, trumpeters compensated for the difficulty in playing in the upper register by using idiomatic devices such as glissandi, trills, flutter-tonguing, and double and triple tonguing.

Finally, although some of the finest performances by less experienced musicians were similar in standard to the better responses of the more advanced musicians, there was (p. 599) one further dimension that was mentioned by all evaluators. More experienced students were more likely to "stretch out" during their performance, to take chances and to attempt things that may not have been possible by their less experienced counterparts. The best performances were more "catchy" and memorable, and consequently, there was a feeling that the older, more mature students had a richer vein of prior experiences (p. 600) from which to tap during their performance. It was only the highest-scoring students who were able to reach out beyond the notes and to perform with expression and 
the highest technical control. It was as if these performers had fully assimilated the technical, aesthetic, theoretical, and kinesthetic dimensions of their playing into one.

\section{Conclusions}

The main points discussed in this chapter can be summarized as follows.

1. Second performances on the six "stylistically conceived" items of the TAI were not statistically significantly better than first attempts.

2. For the shorter improvised tasks (i.e., Closing Phrase $1 \&$ Closing Phrase 2) the best responses came from students who had mentally prepared their response before commencing to improvise. In this way, the better improvisers were characterized by their ability to commence a performance with an overall strategy or plan.

3. The less sophisticated improvisers worked at a conscious level, not yet having assimilated the technical, aural, kinesthetic, and theoretical aspects of their playing.

4. Better improvisers performed with technical control and theoretical understanding of the requirements of the task. However, a distinguishing characteristic of the very finest improvisers was their ability to reach out beyond the norm to provide a response that was unique or novel. Examples of "stretching out" can be seen in the wider choice of starting notes, the more sophisticated sense of shaping, greater use of expression and tone color, and an intuitive feel for the harmonic implications of their response. The integration of each of these aspects helped to make these responses unique.

5. There was evidence in the rhythm item that translating the visual notation into an auditory image clearly impeded fluency and spontaneity. This is similar to observations by jazz educators (e.g., Baker, 1979), who comment that improvisation by sight stifles creativity and instrumental fluency.

6. The best responses for the freely conceived item came from students whose first idea provided the basis or "spark" to ignite their imagination and provide coherence to the rest of the improvisation. Typically the better the quality of opening statement the better the overall performance. Also of critical importance to an effective performance was the ability of the improviser to sustain the flow of ideas, to connect ideas, and to end their performance musically and with a sense of finality.

7. Some gender differences were evident in the responses on the freely conceived item, especially for the more proficient students. Typically, female students tended to play moody, atmospheric improvisations that were often slower and had more space and rests. Some were free in style, displaying a sophisticated sense of phrasing and time. Some of these responses suggest the influence of prior exposure to (p.601) composition experiences in classroom elective music classes. Male students on the other hand, were likely to provide more outgoing, faster, and busier improvisations than females. Many of these performances used a jazz or pop idiom and were more like the improvisations one would expect in a stage ensemble performance of a jazz or rock arrangement. 
8. Differences were also observed between the instruments studied in this investigation. Clarinetists were more likely to use a wider range, employ larger leaps, and use other idiomatic devices typical of performance on this instrument. Likewise, trumpeters compensated for the difficulty in playing in the upper register by using such idiomatic devices as glissandi, trills, flutter-tonguing, and double and triple tonguing.

In all of my work across the past 25 years, I have argued that a "balanced" approach to the development of "musicianship" on a musical instrument can be defined by the ability of a musician to perform music visually (sight-reading, performing rehearsed repertoire), aurally (by ear and from memory), and creatively (improvising).

These orientations are depicted in Figure 25.22, which shows multiple ways in which a teacher can introduce new material and approach the teaching of a range of performance skills. Such an approach is bound to be quite different from normal "traditional" styles of training, and is used here to describe some alternative strategies that could form the basis of teaching at all levels of instruction. For example, moving around the cycle anticlockwise a teacher could introduce a new melody by ear, ask students to improvise their own version of the melody by embellishing and varying it, and then teach them how to read the original melody or their own version using musical notation. After class the student could use the notation as the basis from which to transpose the melody to other keys. The sequence of activities suggested here would be visual to aural to creative and (with the out-of-class activity) visual to aural.

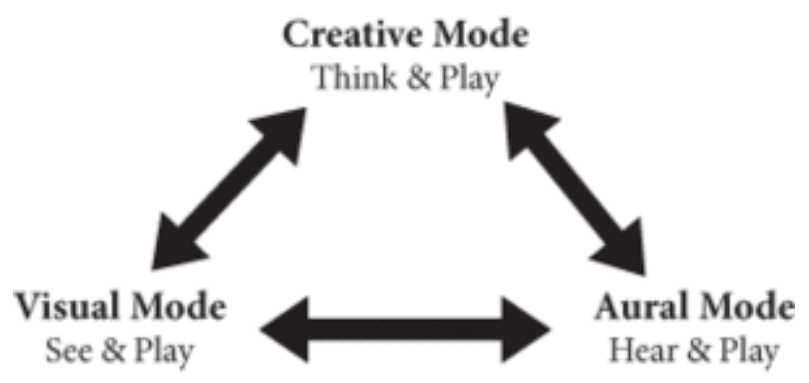

Figure 25.22 Orientations for music performance and learning.

Examples of moving clockwise around the cycle would be activities such as the following. As a warm-up activity at the beginning of a lesson a teacher could start with a rhythmic pattern that is introduced using notation. Students would be encouraged to improvise in a specified key using only the durations of the rhythm pattern, to teach their own version to their classmates, and then to notate their own improvised composition using notation. Likewise, a short melodic motif can be introduced using notation, used as the basis from which to improvise an appropriate melody (by extending, elaborating, and embellishing the motif), and then refined into a final replicable composition, (p. 602) which could be notated during the students' daily "music time" and transposed to different pitch levels. There are an infinite variety of ways in which the cycle shown in Figure 25.22 could be used to construct enjoyable and educationally valuable activities. Most of all, these activi- 
ties would help strengthen a range of skills and foster musically independent instrumentalists. Fundamentally, these activities would also encourage students to "think in sound" before comparing their reproduced version with their internalized model (Schleuter, 1984; p. 26). The sound, therefore, precedes the symbol.

Of course, in any teaching there will be lessons in which students work predominantly from notation, but as suggested here, there should always be opportunities for aural and creative activities at some point in a lesson. These strategies are clearly of more benefit than teaching that stresses only one type of performance, and in which a student's progression is governed by what the next tune in the book happens to be. In this way, improvisation is a key skill for all musicians to learn and experience (McPherson, Davidson, \& Faulkner, 2012).

In my opinion, an important goal for teaching students musical instruments is to nurture their talent so that they are capable of reaching their full potential and thus better equipped to cope with the demands of music making in a wider sense. The human need to improvise and learn by creating music, rather than just reproducing music, is a powerful force that can be used to drive and motivate musicians during all stages of their development.

\section{References}

Aitken, A. E. (1975). A self-instructional audio-imitation method designed to teach trumpet students jazz improvisation in the major mode (Doctoral dissertation). Retrieved from University Microfilms International. (76-15018).

Baker, D. N. (1969). Jazz improvisation. Chicago, IL: Maher Publications.

Baker, D. N. (1979). Advanced improvisation. Chicago, IL: Music Workshops Publications.

Berkowitz, S. (1975). Improvisation through keyboard harmony. Englewood Cliffs, NJ: Prentice-Hall.

Briscuso, J. J. (1972). A study of ability in spontaneous and prepared jazz improvisation among students who posses different levels of musical aptitude (Unpublished doctoral dissertation). University of Iowa, Iowa City, IA.

Burnsed, C. V. (1978). The development and evaluation of an introductory jazz improvisation sequence for intermediate band students (Doctoral dissertation). Retrieved from Dissertation Abstracts International. (79-1, 829).

Campbell, P. S. (1990). Crosscultural perspectives of musical creativity. Music Educators Journal, 76(9), 43-46. doi: 10.2307/3401077

Campbell, P. S. (1991). Unveiling the mysteries of musical spontaneity. Music Educators Journal, 78(4), 21-24. 


\section{Developing Tests of Music Performance Improvisation}

Campbell, D. T., \& Fiske, D. W. (1959). Convergent and discriminant validation by the multitrait-multimethod matrix. Psychological Bulletin, 56(2), 81-105.

Chase, M. P. (1988). Improvisation: Music from the inside out. Berkeley, CA: Creative Arts Book Company. doi: 10.2307/3398332

(p. 603) Coker, J. (1964). Improvising jazz. Englewood Cliffs, NJ: Prentice-Hall.

Dale, B. J., Jacob, G., \& Anson, H. V. (1940). Harmony, counterpoint, improvisation: Book II. London, UK: Novello and Company.

Damron, B. L. (1973). Developing and evaluating a self-instructed sequence in jazz improvisation (Doctoral dissertation). Retrieved from Dissertation Abstracts International (35, 1141A).

Dean, R. (1989). Creative improvisation: Jazz, contemporary music and beyond. Milton Keynes, UK: Open University Press.

Department of Education and Science. (1990). Music from 5 to 16: Curriculum matters 4. London, UK: Her Majesty's Stationery Office.

Dickinson, P. (1964b). Improvisation 2: Interval and melodic pattern. Musical Times, 105, 377-378.

Dickinson, P. (1964a). Improvisation 3: Simple accompaniments and chords. Musical Times, 105, 538-539.

Dickinson, P. (1964b). Improvisation 5: Design. Musical Times, 105, 688-690.

Dickinson, P. (1964c). Improvisation 4: Rhythm and texture. Musical Times, 105, 612-614.

Flohr, J. W. (1979). Musical improvisation behavior of young children (Unpublished doctoral dissertation). University of Illinois, Urbana-Champaign, IL.

Frackenpohl, A. (1985). Harmonization at the piano (5th ed.). Dubuque, IA: Wm. C. Brown.

Frazee, J. (1987). Discovering Orff: A curriculum for music teachers. New York, NY: Schott.

Froseth, J., \& Blaser, A. (1980). Studies in creative musicianship: Ear training for musical improvisation: Levels $1 \& 2$. Chicago, IL: GIA Publications.

Gorder, W. D. (1976). An investigation of divergent production abilities as constructs of musical creativity (Unpublished doctoral dissertation). University of Illinois, UrbanaChampaign, IL.

Gorder, W. D. (1980). Divergent production abilities as constructs of musical creativity. Journal of Research in Music Education, 28(1), 34-42. doi: 10.2307/3345051 


\section{Developing Tests of Music Performance Improvisation}

Gordon, E. E. (1989). Learning sequences in music. Chicago, IL: GIA Publications.

Guilford, J. P. (1967). The nature of human intelligence. New York, NY: McGraw-Hill.

Guilford, J. P., \& Hoepfner, R. (1971). The analysis of intelligence. New York, NY: McGrawHill.

Hargreaves, D. J., Cork, C. A., \& Setton, T. (1990). Cognitive strategies in jazz improvisation: An exploratory study. Canadian Music Educator: Research Edition, Special ISME Research Edition, 33, 47-54.

Harvey, E. (1988). Jazz in the classroom: Practical sessions in jazz and improvisation. London, UK: Boosey \& Hawkes.

Hunt, R. (1968). Extemporization for music students. London, UK: Oxford University Press.

Judy, S. (1990). Making music for the joy of it: Enhancing creativity, skills, and musical confidence. Los Angeles, CA: Jeremy P. Tarcher, Inc.

Kratus, J. (1990). Structuring the music curriculum for creative learning. Music Educators Journal, 76(9), 33-37. doi: 10.2307/3401075

McDaniel, W. T. (1974). Differences in music achievement, musical experience, and background between jazz improvising musicians and non-improvising musicians at the freshman and sophomore college levels (Doctoral dissertation). Retrieved from University Microfilms International. (75-13794).

McPherson, G. E. (1993). Factors and abilities influencing the development of visual, aural and creative performance skills in music and their educational implications (Doctoral dissertation). Retrieved from Dissertation Abstracts International. (54/04-A, 1277).

McPherson, G. E. (1995). The assessment of musical performance: Development and validation of five new measures. Psychology of Music, 23, 142-161. doi:

$10.1177 / 0305735695232003$

(p. 604) McPherson, G. E. (2005). From child to musician: Skill development during the beginning stages of learning an instrument. Psychology of Music, 33(1), 5-35. doi: $10.1177 / 0305735605048012$

McPherson, G. E., Davidson, J., \& Faulkner, R. (2012). Music in our lives: Rethinking musical ability, development and identity. Oxford, UK: Oxford University Press.

Moore, J. L. S. (1990). Strategies for fostering creative thinking. Music Educators Journal, 76(9), 38-42. doi: 10.2307/3401076

Nicholls, F., \& Tobin, J. R. (1937). Adventures in improvisation. London, UK: Joseph Williams. 


\section{Developing Tests of Music Performance Improvisation}

Partchey, K. C. (1973). The effects of feedback, models, and repetition on the ability to improvise melodies (Unpublished doctoral dissertation). Pennsylvania State University, State College, PA.

Pfenninger, R. C. (1990). The development and validation of three rating scales for the objective measurement of jazz improvisation achievement (Unpublished doctoral dissertation). Temple University, Philadelphia, PA.

Pressing, J. (1988). Improvisation: Methods and models. In J. Sloboda (Ed.), Generative processes in music (pp. 128-178). New York, NY: Oxford University Press.

Priest, P. (1985, March). Playing by ear. Music Teacher, 64(3), 10-11.

Priest, P. (1988). Playing by ear: An investigation of the phenomenon and of its potential for instrumental learning as part of music education (Unpublished masters thesis). University of London, London, UK.

Priest, P. (1989). Playing by ear: Its nature and application to instrumental learning. British Journal of Music Education, 6, 173-191.

Rosfeld, M. D. (1989). The development of a series of instructional units for teaching improvisational principles to pianists (Unpublished doctoral dissertation). University of Oklahoma, Norman, OK.

Rowley, A. (1955). Extemporization: A treatise for organists. New York, NY: Mills Music.

Sawyer, F. J., (1923). Extemporization. London, UK: Novello.

Schilling, R. (1989). The construction and validation of rating scales for the objective measurement of jazz improvisation achievement. Pennsylvania Music Educators Association, May.

Schleuter, S. L. (1984). A sound approach to teaching instrumentalists: Application of content and learning sequences. Kent, $\mathrm{OH}$ : The Kent State University Press.

Schlieder, F. (1927). Lyric composition through improvisation. Boston, MA: C.C. Birchard.

Simpson, K. (1963). Keyboard harmony and improvisation. London, UK: Alfred Lengnick.

Stubington, H. (1940). Practical extemporization. London, UK: The Epworth Press.

Swanwick, K., \& Tillman, J. (1986). A sequence of musical development: A study of children's compositions. British Journal of Music Education, 3, 305-339.

Texter, M. (1979). Musicianship in the beginning instrumental class. Reston, VA: Music Educators National Conference.

Thackray, R. M. (1968). Creative music in education. London, UK: Novello. 


\section{Developing Tests of Music Performance Improvisation}

Thackray, R. M. (1978). Aural awakening. Perth, Western Australia: University of Western Australia Press.

Torrance, E. (1966). Norms-technical manual: Torrance tests of creative thinking. Bensenville, IL: Scholastic Testing Service.

Vaughan, M. M. (1971). Music as model and metaphor in the cultivation and measurement of creative behavior in children (Unpublished doctoral dissertation). University of Georgia, Athens, GA.

Webster, P. R. (1977). A factor of intellect approach to creative thinking in music (Unpublished doctoral dissertation). University of Rochester, Rochester, NY.

(p. 605) Webster, P. R. (1979). Relationship between creative behavior in music and selected variables as measured in high school students. Journal of Research in Music Education, 27, 227-242. doi: 10.2307/3344710

Webster, P. R. (1983a). Refinement of a measure of musical imagination in young children and a comparison to aspects of musical aptitude. Paper presented at the Armington Symposium, Case Western Reserve University, Cleveland, $\mathrm{OH}$.

Webster, P. R. (1983b). An assessment of musical imagination in young children. In P. Thomas Tallirico (Ed.), Contributions to the symposium 83: The Bowling Green State University symposium on teaching and research. Bowling Green, $\mathrm{OH}$ : Bowling Green State University.

Webster, P. R. (1989). Creative thinking in music: The assessment question. In J. W. Richmond (Ed.), The proceedings of the Suncoast Music Education Forum on Creativity (pp. 40-74). Tampa, FL: University of South Florida.

Whittlich, G. E., \& Martin, D. S. (1989). Tonal harmony for the keyboard. New York, NY: Schirmer Books.

Wunsch, I. G. (1972, June/July). Improvisation ... how? The American Music Teacher 21(6), 22-23.

\section{Gary E. McPherson}

Gary E. McPherson studied music education at the Sydney Conservatorium of Music, before completing a master of music education at Indiana University, a doctorate of philosophy at the University of Sydney and a Licentiate and Fellowship in trumpet performance through Trinity College, London. He is the Ormond Professor and Director of the Melbourne Conservatorium of Music and has served as National President of the Australian Society for Music Education and President of the International Society for Music Education. His research interests are broad and his approach interdisciplinary. His most important research examines the acquisition and development of musical competence, and motivation to engage and participate in music from novice 
to expert levels. With a particular interest in the acquisition of visual, aural and creative performance skills he has attempted to understand more precisely how music students become sufficiently motivated and self-regulated to achieve at the highest level. 


\section{University Library}

\section{- M M I N E R VA A gateway to Melbourne's research publications}

Minerva Access is the Institutional Repository of The University of Melbourne

Author/s:

McPherson, GE

Title:

Developing Tests of Music Performance Improvisation

Date:

2019-03-08

Citation:

McPherson, G. E. (2019). Developing Tests of Music Performance Improvisation. Brophy, TS (Ed.). The Oxford Handbook of Assessment Policy and Practice in Music Education, Volume 1, (1), pp.573-605. Oxford University Press.

Persistent Link:

http://hdl.handle.net/11343/285314 